\title{
Reagregando o Biopsicossocial: a clínica da dor sob análise etnográfica ${ }^{1}$
}

\author{
Mário Eugênio Saretta ${ }^{1}$
}

${ }^{1}$ Universidade Federal do Rio Grande do Sul, Porto Alegre, RS, Brasil

\section{Resumo}

A análise da dor de orientação biomédica costuma destacar o aspecto biopsicossocial da dor crônica, característica que requereria uma abordagem analítica multidisciplinar. No entanto, como a noção de conjunto social é mobilizada nessa síntese? Interessado em enactments da prática clínica da medicina especializada em dor crônica, analiso como as práticas compõem (in)distinções que envolvem o biológico, o psicológico e o social. Influenciado pelos estudos antropológicos da ciência, do corpo e da saúde, priorizarei neste artigo a descrição etnográfica de consultas e de discussões de casos clínicos em um hospital universitário para sugerir que fronteiras biossociais são instáveis e exigem coordenações ontológicas. Desse modo, indicarei que o corpo com dor crônica delimitado em uma consulta se mostra atravessado por políticas públicas, relações familiares, estratégias econômicas, materialidades e desejos diversos, por isso se torna resistente ao completo isolamento analítico dos fatores discriminatórios capazes de estabilizarem biologia, psicologia e relações sociais.

Palavras-chave: Antropologia da dor. Antropologia da Saúde. Etnografia de Hospital. Antropologia da Ciência. Enactments.

\section{Reassembling the Biopsychosocial: chronic pain clinic from an ethnographic point of view}

\begin{abstract}
Even biomedical analysis usually highlights the biopsychosocial aspect of chronic pain, associated with disease and illness from a multidisciplinary perspective. However, how is a notion of social mobilized in the biopsychosocial approach? Interested in enactments of the clinical practice of medicine specialized in chronic pain, I will analyze how these practices comprise (in)distinctions involving the biological, the psychological and the social. Influenced by science and technological studies and medical anthropological researches, I will prioritize in this article an ethnographic description of clinical cases in a teaching hospital to suggest which biosocial boundaries are unstable and are dependent of ontological coordinations. I will argue that the body with chronic pain delimited in a medical appointment is shaped by public policies, family relationships, economic strategies, material and diverse desires, so it becomes resistant to the complete analytical isolation of discriminatory factors capable of stabilizing biology, psychology and social relationships.
\end{abstract}

Keywords: Medical Anthropology. Anthropology of Pain. Hospital Ethnography. Science Studies. Enactments.

\footnotetext{
1 Artigo foi elaborado a partir da tese intitulada Feitos e efeitos do placebo: corpo, dor e realidade a partir da antropologia social (SARETTA, 2019), que recebeu o prêmio de melhor tese da Região Sul/Centro-Oeste/DF do Concurso Brasileiro ANPOCS de Obras Científicas e Teses Universitárias em Ciências Sociais 2020. 


\section{Introdução}

1 aquela palavra mágica que eu adoro: a dor é biopsicossocial". Com essa afirmação, concluiu sua arguição sobre a complexidade da dor crônica. A ênfase no caráter multifatorial era uma explicação didática dada aos profissionais de diversas áreas ali presentes na condição de alunos de um curso de especialização em dor. Ao mesmo tempo, demarcava o seu posicionamento diante de um caso clínico apresentado para o qual defendia que seria insuficiente o ajuste de dosagem ou a prescrição de uma nova medicação. A afirmação conclusiva sobre o caráter biopsicossocial da dor, que era o fim do relevante raciocínio sobre a complexidade do caso em análise, parecia indicar um bom começo à minha investigação antropológica: compreender como práticas relacionadas à medicina especializada em dor compõem (in)distinções que envolvem o biológico, o psicológico e o social.

A proposição do modelo biopsicossocial para análise da dor crônica é uma tentativa médica de ampliar o foco historicamente dado aos mecanismos sensórios para abranger também fatores cognitivos, afetivos, comportamentais e homeostáticos (GATCHEL et al., 2007, p. 584). Em meados do século XX, houve uma mudança da concepção hegemônica no tratamento da dor crônica quando a medicina deixou de buscar a cura por meio de técnicas para priorizar o gerenciamento da dor a ser tratada em clínicas e centros especializados, compostos de uma equipe multidisciplinar que incluía um representante da psiquiatra ou da psicologia clínica (BASZANGER, 1998). Nas décadas seguintes, teorias biomédicas sobre a modulação da dor (a Teoria do Portão e, mais recentemente, a Teoria da Neuromatriz) forneceram a base teórica capaz de consolidar essa mudança analítica de modo que, atualmente, a experiência dolorosa tem sido compreendida como dependente da interação de diferentes regiões cerebrais (TRACEY; MANTYH, 2007, p. 379).

É nesse sentido que mesmo os profissionais embasados na biomedicina reconhecem o caráter multifatorial da dor crônica, motivo pelo qual o modelo biopsicossocial costuma ser frequentemente referenciado pelos profissionais especializados nessa condição dolorosa. Conforme destacam Gatchel et al. (2007), esse modelo tem a pretensão de abranger a doença como um todo ao abarcar a disease (entendida como um evento biológico objetivo envolvendo a ruptura de estruturas corporais específicas causada por mudanças anatômicas, patológicas ou fisiológicas) e a illness (entendida como uma experiência subjetiva ou autoatribuição da presença da disease). A parte bio seria constituída pela predisposição genética, pela nocicepção e por outros processos neurocientíficos, enquanto a parte psicossocial envolveria emoção e cognição e aspectos da vida cotidiana 
vinculados diretamente ao chamado social, como relações interpessoais, ambiente familiar, expectativas sociais, fatores culturais, experiências de tratamentos prévios e histórico de trabalho (GATCHEL et al., 2007, p. 583).

No livro Antropologia da Dor, David Le Breton (2013) explicita que há diferentes significados e usos sociais da dor e que relações culturais como atividades religiosas e rituais podem modificar completamente limites relacionados à percepção e à intensidade de sintomas dolorosos. Le Breton (2013, p. 172) se mostra otimista quando considera que a dor imporia um novo paradigma para a medicina na passagem de uma medicina do corpo a uma medicina centrada em toda dimensão identitária humana, visto que o vínculo social seria um elemento determinante da sensação de dor. Destaco que meu interesse neste artigo não é voltado para a variação da intensidade relacionada ao âmbito social enquanto significado cultural, mas, sim, para a compreensão de como aspectos sociais se expressariam junto aos biológicos na análise do corpo doloroso pela medicina clínica.

Para compreender o que ocorre em hospitais, Annemarie Mol (2002) propõe que a pesquisa etnográfica privilegie práticas em lugar de princípios, procedimentos clínicos e seus aparatos mais do que operações cognitivas de médicos. Tal abordagem reconhece que há multiplicidade mesmo na biomedicina. Nesse sentido, “[...] o que é aglutinado se transforma em uma questão em aberto. A questão de como objetos, sujeitos, situações e eventos são diferenciados em elementos separados e como eles são coordenados juntos é aberta ao estudo" (MOL, 2002, p. 83, tradução e grifos meus). É nesse sentido que a pesquisa etnográfica será apresentada neste artigo, no qual buscarei analisar a racionalidade médica em ato mais do que as orientações presentes em manuais ou diretrizes de tratamento.

Com essa pretensão antropológica, com o intuito de desenvolver uma pesquisa mais ampla voltada para o efeito placebo (SARETTA, 2019), meu projeto foi aprovado pelo comitê de ética em pesquisa de um hospital universitário, onde passei a acompanhar consultas ambulatoriais em seu Serviço de Tratamento de Dor ao longo de aproximadamente dois anos. As consultas demandam discussão e análise de preceptores (médicos especializados em dor contratados pelo hospital) a partir de um atendimento inicialmente feito por médicos residentes e/ou profissionais do curso multidisciplinar de especialização profissional em dor e cuidados paliativos oferecido por esse serviço e/ou estudantes de medicina na fase final do curso de graduação (chamados de doutorandos). Semanalmente, os preceptores e os demais estudantes e profissionais em especialização realizam rounds com a equipe do programa de psiquiatria e dor, coordenado por um psiquiatra especializado em dor que integra o referido serviço. Esses encontros são dedicados a discussões coletivas sobre casos clínicos em que fatores psicológicos e/ou psiquiátricos são considerados especialmente importantes na etiologia da dor. Acompanhei diversos rounds e mais de uma centena de consultas: por vezes todas as etapas, outras vezes as discussões e a posterior visita de preceptores ao consultório e, em alguns casos, exclusivamente as discussões.

Pelo fato de haver atividades acadêmicas de pesquisa e ensino além do atendimento clínico, o serviço estudado pode ser classificado como um Centro Multidisciplinar de Tratamento de Dor, conforme critério da International Association for the Study of Pain (IASP), associação de referência mundial no tratamento da dor e editora de uma revista com artigos científicos originais sobre a temática. Centros desse tipo necessitam ser 
multidisciplinares e contar com todos profissionais especializados no gerenciamento da dor, trabalhando em um mesmo espaço e se comunicando com frequência, orientados por um programa centrado no paciente e considerado atualizado, seguro e baseado em evidências. Todos integrantes dos Centros Multidisciplinares de Tratamento de Dor devem ter conhecimento da influência de fatores biológicos, psicológicos e sociais nos problemas relacionados à dor e devem ser capazes de tratar qualquer tipo de dor, motivo pelo qual necessitam ter acesso a consultorias médicas de outras especialidades. A IASP sugere segmentos que deverão ser combinados na abordagem biopsicossocial e designa a necessidade de uma contínua produção de medidas sobre a intensidade de dor, o sofrimento psicológico, a funcionalidade e a qualidade de vida dos pacientes avaliados e tratados ${ }^{2}$.

Em 2018, estive presente no $17^{\text {th }}$ World Congress on Pain, evento organizado pela IASP nos Estados Unidos da América, no qual vi com frequência a projeção de slides contendo três círculos ou triângulos representando os elementos bio, psico e social que se interseccionavam no meio, região na qual havia a palavra dor. Em conversa com um palestrante que é referência mundial no estudo do efeito placebo relacionado à dor, ele se surpreendeu com minha presença enquanto antropólogo social e nós dois consideramos que eu provavelmente seria o único profissional dessa área ali presente.

As únicas duas mesas redondas dessa edição do congresso em que os títulos indicavam protagonismo ao aspecto social sem que o termo fosse precedido pelos prefixos biopsico ou psico coincidiram em dia e horário. Uma delas se referia a tendências, ausências e novas direções de pesquisas relacionadas ao suporte social ao longo da vida de pessoas com dor crônica. A outra mesa, na qual optei por estar presente, intitulava-se Dor em um Contexto Social. Suas apresentações se relacionaram a experimentos com ratos em laboratório para analisar o uso de farmacoterapia analgésica conciliada com a habitação em um ambiente considerado socialmente enriquecedor; a um experimento que pretendia medir a distância que universitários sentariam de uma pessoa desconhecida que atuava fingindo comportamento doloroso; a aplicação de questionários em um estudo focal sobre sentimento de injustiça relacionado à dor; e, por fim, a um estudo com medidas respiratórias, cardíacas e cerebrais para analisar a sincronia biológica do efeito da empatia a partir do toque físico em pessoas com dor. Em outra mesa do evento, relacionada a gênero e dor, encontrei análises mais próximas àquelas que reconheço como antropológicas, mas o debate era restrito a explorar estereótipos de masculinidades que tentavam exibir resistência à dor durante testes clínicos de pesquisa.

Desse modo, torna-se evidente que, embora o modelo biopsicossocial apresentado pela IASP reforce os componentes sociais e a importância da multidisciplinaridade, há uma pressuposição de conjunto social que não integra - mais do que isso, parece afastar - antropólogos sociais. Essa constatação parece indicar a relevância de analisar como a dimensão social é mobilizada na prática clínica junto às dimensões biopsicológicas, o que é meu objetivo neste artigo. Orientado pelos estudos antropológicos da ciência, do corpo e da saúde, priorizarei a descrição etnográfica de consultas e de discussões de casos clínicos para sugerir que fronteiras biossociais são instáveis e que a definição clínica

2 Para características completas exigidas pela IASP a um Centro Multidisciplinar de Tratamento de Dor, consultar: https://www.iasp-pain.org/Education/Content.aspx?ItemNumber=1381 (Acessado em: 4 abr. 2019). 
do que causa a dor demanda definir corpo, delimitar autoridades, redistribuir noções causais, reordenar identidades.

Tais análises me foram possibilitadas porque o referido Serviço de Tratamento de Dor contava com profissionais receptivos à minha proposição de pesquisa inusitada àquele ambiente, a qual me permitia o privilégio de poder desenvolver uma análise sem necessitar definir uma estratégia terapêutica direcionada a ajudar algum paciente específico. Minhas impressões de pesquisador encontraram espaço para o diálogo, mesmo que eu não estivesse na condição de terapeuta. Desse modo, expresso meu agradecimento aos preceptores e destaco que, dentre aqueles que leram minhas descrições etnográficas, um deles considerou que a ausência de descritores clínicos para a dor de cada paciente atendido (característica dolorosa neuropática, nociceptiva ou nociplástica) ocasionaria menos destaque à importância dos fatores biológicos. Por esse motivo, faço esta ressalva: ainda que eu não os explicite individualmente, eles são sempre considerados pela análise médica e são determinantes para a prescrição das terapêuticas. Saliento também que, durante os atendimentos clínicos e as discussões de caso, profissionais parecem assumir posturas menos flexíveis do que em momentos de afirmações científicas ou de debate de casos complexos - nessas condições, ouvi diversas vezes o então coordenador do serviço corrigir alunos e residentes sobre inferências precipitadas de relações causais, rememorando que "medicina não é matemática".

Tendo em vista preservar o anonimato de pacientes e não confundir o leitor ou a leitora com uma proliferação de pseudônimos, optarei por utilizá-los apenas em descrições extensas. Em relação a preceptores, utilizarei o termo sempre no masculino porque no período e turnos que acompanhei o referido serviço havia apenas uma preceptora sistematicamente presente, motivo pelo qual o termo no feminino poderia sugerir sua identificação. No caso de residentes, doutorandos e cursistas, mantive a diferenciação de gênero porque se referem a uma grande diversidade de pessoas. Em casos de plural de substantivo com diversidade de gênero, utilizarei aleatoriamente termos no masculino e feminino, contrariando a orientação gramatical geral de língua portuguesa de que os plurais sejam conjugados no masculino quando há ao menos um elemento desse gênero no conjunto ou quando há referência a um sujeito universal.

\section{Reagregando o Biopsicossocial}

In practice the body and its diseases are more than one, but this not mean that they are fragmented into being many. (MOL, 2002, p. VIII)

$\mathrm{Na}$ análise antropológica fundadora da compreensão do corpo como objeto e meio técnico, Marcel Mauss (2003) se referia ao "homem total", composto de um tríplice ponto de vista que conjugaria os elementos biológico (anatômico e fisiológico), psicológico e sociológico. Assim, reconhecia que o corpo em seu conjunto seria "[...] condicionado pelos três elementos indissoluvelmente misturados" (MAUSS, 2003, p. 405). Essa distinção parece também assumida pelas análises antropológicas que priorizam a illness na construção de um objeto de pesquisa que foi por muito tempo negligenciado: a experiência do paciente que sente dor. Considerada como uma característica universal 
da condição humana, a dor é analisada nessa perspectiva como um constructo cultural, incluindo os modos como é vista e sentida como algo estritamente biológico (GOOD et al., 1992; JACKSON, 2000).

Nesse sentido, pesquisadores editores do livro Pain as Human Experience: an Anthropological Perspective (GOOD et al., 1992, p. 14) consideravam que a antropologia da dor, diferentemente da biologia e da psicologia da dor, deveria realizar a comparação das causas, características e implicações da transformação da condição humana no ocidente em contraste com outras sociedades e outros tempos. O centro da análise antropológica seria, assim, os efeitos diários da dor, as biografias daqueles que sofrem, suas trajetórias na família e no trabalho, os tratamentos e os efeitos de forças sociais sobre cada elemento da experiência da dor. Portanto, a doença em si mesma (disease) não seria objeto nem de suas pesquisas nem da antropologia social.

Mesmo realizando essa distinção rigorosa entre doenças como um fenômeno biológico e como uma experiência vivida, Jean Jackson (2000) destaca com pertinência que o diagnóstico e o tratamento da dor seriam difíceis porque perpassariam visões da medicina sobre corpo e mente, sobre saúde e doença, sobre responsabilidade moral. Algumas análises etnográficas de clínicas de dor consideram que o limite entre o físico e o psicológico seria um fator ambíguo para os médicos devido à dificuldade de delimitação (LIMA; TRAD, 2007) e que a medicina psicossomática acabaria por reforçar esse divisor em suas explicações apesar de ter intuído o exagero da separação cartesiana entre dor física e espiritual (GUERCI; CONSIGLIERI, 1999).

Minha proposição analítica neste artigo é influenciada pela filosofia da diferença e da ciência (DELEUZE; GUATTARI, 1995; 1996; STENGERS, 2002; 201 1; DESPRET, $2004 ; 2011$ ) e pelos efeitos da antropologia da ciência e da tecnologia na análise do corpo (LATOUR, 2005; HARAWAY, 2009; BERG; MOL, 1998; BERG; AKRICH, 2004; MOL, 2002; 2008; LOCK; NGUYEN, 2010; M'CHAREK, 2010; ROHDEN, 2018a; 2018b). Assim, recusando conceber a disease como um objeto preexistente e indiferente à illness, busco analisar conexões parciais que ocorrem na prática clínica por meio de enactments (MOL, 2002 ) que compõem o biológico, o psíquico e o social unidos na síntese biopsicossocial. Para isso, passo a me dedicar às descrições etnográficas a partir da consulta de Luana que, ao adentrar a um dos consultórios do Serviço de Tratamento de Dor, entregou exames clínicos que realizara a pedido de profissionais do posto de saúde, os quais a haviam encaminhado para este ambulatório especializado.

Enquanto uma doutoranda olhava os exames, a outra perguntou à Luana como eram suas dores, como estava seu sono, quais os horários em que se deitava e se levantava da cama, quais esforços físicos fazia em sua rotina e onde lhe doía precisamente. As informações consideradas relevantes foram anotadas no prontuário, que possui uma estrutura padrão orientada pelas categorias subjetivo, objetivo, conduta e impressões. Por esse motivo, os médicos geralmente copiam os dados da última sessão para editá-los durante o novo atendimento.

A doutoranda atualizou as dosagens das medicações em uso e depois perguntou à paciente se ela teria melhorado após as prescrições de sua primeira e única consulta neste serviço. Pediu-lhe que se sentasse na maca e que empurrasse sua perna fazendo força contra a mão da acadêmica, que tentava conter o movimento. Isso também foi 
feito com a outra perna e com os braços para analisar se haveria o que é definido do ponto de vista médico como perda de força muscular. Quando saímos do consultório, as doutorandas relataram a um preceptor os componentes essenciais de serem verificados nos casos de dor crônica: a característica e a intensidade da dor, a qualidade do sono e o humor (bem-estar emocional). O preceptor perguntou às doutorandas a data em que a paciente começou a sentir dor, como estavam suas relações afetivas e se ela dormia bem à noite. Ao vê-la, fez uma série de perguntas. Durante as respostas, ele se direcionava às doutorandas brevemente por meio de alertas tais como "viram só?", "estão vendo?", "isso não me falaram, mas é importante", utilizando a consulta para a prática de ensino, uma das principais funções deste hospital universitário.

Após ter sido questionada sobre sua profissão, as características da dor e o período de surgimento, Luana mencionou ter dificuldade para segurar o intestino, o que foi registrado no prontuário como incontinência fecal. O preceptor sugeriu que o sintoma relatado neste contexto teria uma relação causal não aleatória, por isso perguntou se houve algo grave em sua vida. A paciente não mencionou nada determinante, mas expressou um leve constrangimento ao falar sobre o assunto. Ele perguntou como estava sua relação conjugal e ela contou que estava planejando se divorciar porque o marido teria "aprontado". A partir de então, a consulta passou a se apoiar em um novo objeto de investigação: não diretamente o corpo anatômico da paciente, mas o efeito da traição, agora explorado tanto quanto a possível perda de força muscular. Luana contou que o marido era alcoólatra (no prontuário, tornou-se alcoolista) e lhe batera até denunciá-lo à delegacia de polícia, amparada pela Lei Maria da Penha, exclusiva para casos de abuso contra mulheres. O marido, então, foi obrigado a fazer tratamento em um Centro de Atenção Psicossocial (CAPS), o que teria melhorado seu comportamento. Questionada se ele ainda lhe agredia, declarou: "Não, só verbalmente".

Luana disse também que não compartilhavam mais a mesma cama e seguiu respondendo às perguntas detalhadas sobre as razões pelas quais ainda não havia se divorciado, sobre o possível medo de uma nova agressão e, por fim, se a porta do seu quarto permanecia aberta ou fechada durante a noite. "Aberta". Depois de um período de silêncio, justificou que não havia porta no cômodo. O preceptor perguntou uma série de questões específicas: o horário em que ela se deitava na cama, se dormia imediatamente, se possuía despertares noturnos, se levantava para ir ao banheiro durante a madrugada, o horário em que acordava. A paciente repetiu o mesmo horário em que se deitava na cama mencionado às doutorandas, mas acrescentou que demorava em torno de duas horas para conseguir dormir, o que o médico caracterizou como insônia.

Ele repetiu os exames de força muscular realizados previamente pelas doutorandas, confirmando a sua capacidade motora, e pediu que ela retirasse a calça e cobrisse com um lençol a região das roupas íntimas. Com o lado oposto à extremidade pontiaguda de uma agulha de acupuntura, percorreu a superfície da panturrilha da paciente questionando se ela sentia o deslocamento do objeto. "E aqui, sente igual ou diferente?", interrogava ao posicionar a agulha sobre diferentes regiões do corpo. No início, Luana pareceu confusa, mas logo compreendeu o funcionamento do exame, porém as respostas não pareciam coerentes ao preceptor, que lhe pediu que fechasse os olhos para ter mais concentração e evitar que a percepção do tato fosse determinada pela visão. 
Em uma parte específica da perna, ela não identificou o toque da agulha. A expressão facial do preceptor demonstrou estranhamento. Ele estimulou, então, ambas as pernas no sentido vertical e passou a se utilizar da extremidade pontiaguda da agulha, testando agora a sensibilidade da paciente por todo o corpo, inclusive a região dos braços e do pescoço, sem nunca perfurar sua pele. A seguir, umedeceu com álcool um algodão e o encostou em diferentes regiões do corpo para analisar se ela possuía sensibilidade à diferença de temperatura. Ele pediu que ela se vestisse enquanto sairíamos para discutir novamente a conduta. Ao lado de fora da sala, comentou conosco que a paciente estaria vivenciando uma situação horrível pelo sentimento de ameaça causado pelo marido. Instruindo as doutorandas sobre elementos importantes de serem analisados, destacou com ênfase que quando alguém se refere a datas precisas sobre o início ou aumento da intensidade da dor, provavelmente há uma correlação que deve ser investigada. Exames laboratoriais e neuroimagéticos foram solicitados.

A diversidade de fatores analisados durante a consulta compõe a complexidade da dor crônica, doença que envolve um campo multidisciplinar de tratamento e de investigação. Na prática clínica, considera-se que dor, humor e sono podem se correlacionar na composição do diagnóstico do corpo doloroso bem como no tratamento, pois algumas drogas agiriam simultaneamente para essas três condições com variação de ênfase, conforme a dosagem, enquanto outros medicamentos teriam indicações mais específicas, embora possam agir nas mesmas regiões neuronais. Em termos médicos, a dor costuma ser compreendida como uma modalidade sensorial complexa essencial à sobrevivência por ser capaz de gerar respostas comportamentais de proteção do organismo ao detectar estímulos com potencial de causar danos (PATEL, 2010, p. 9). Diferentemente da dor aguda, a qual é vista como um processo útil biologicamente, a dor que se atribui cronicidade ${ }^{3}$ é definida pelas ciências médicas como uma dor que perdeu sua função de alerta, tornando-se, assim, um fenômeno mal adaptativo. Frequentemente ouvi residentes ou médicos em processo de especialização em dor sugerirem que o conhecimento regular em suas formações seria voltado ao tratamento da dor aguda, motivo pelo qual muitos deles consideravam até então que a dor crônica estaria necessariamente relacionada a algum tipo de lesão, relação causal abandonada há tempos por análises contemporâneas.

A descrição da consulta mostra como a manipulação do corpo, o exame com objetos e as técnicas de questionamentos assim como os testemunhos, as datas e a cooperação da paciente com o exame clínico são parte dos recursos que produzem a dor como um objeto a ser tratado. O uso da agulha e do algodão para o exame provocou suspeitas de razões neurológicas, que passaram também a compor a expressão daquela dor, assim como a insônia da paciente, que ganhou existência somente após as perguntas específicas do preceptor.

Outras perguntas foram direcionadas para a experiência da paciente em uma tentativa de entender o que em uma discussão de caso ambulatorial talvez fosse descrito como "contexto" e o que em um artigo científico seria atribuído ao componente "social"

\footnotetext{
Utilizo aqui a distinção entre dor crônica e aguda enquanto termos da inteligibilidade médica. Entretanto, concordo com Soraya Fleischer e Mônica Franch (2015, p. 23) quando destacam que classificar doenças como "crônicas" e "agudas" pode não ser profícuo para análises antropológicas, considerando-se, por exemplo, que há doenças tidas como crônicas que possuem evolução fatal, que crises podem ser compreendidas como de longa duração e que interlocutores se utilizam de outros termos, tais como doença de longa duração ou doença comprida.
} 
da dor. No caso de Luana, envolvia a ausência de uma porta que pudesse diminuir o sentimento de ameaça do marido, que já havia sido alterado em função do efeito de uma condenação jurídica que envolveu uma delegacia específica para violência de gênero e um serviço de atendimento psicossocial. Portanto, a arquitetura de sua casa e a política pública também passaram a compor o quadro doloroso a ser tratado, entendido como uma situação de vulnerabilidade social.

Quando o preceptor sugeriu a importância de investigação aprofundada sempre que o surgimento da dor é atribuído a uma data precisa, ele indicava uma provável existência de algum evento - no caso descrito, a traição do marido. Os efeitos de aspectos lidos como psicológicos não são compreendidos pelos profissionais do ambulatório pesquisado ${ }^{4}$ por meio de um referencial psicanalítico, mas, sim, pelos indicativos da neurociência e do paradigma da medicina baseada em evidências. Desse modo, a análise do efeito da traição seria voltada, por exemplo, à "carga alostática" caracterizada pela exposição contínua ao estresse. Assim, a reação do corpo a uma ameaça teria sido prejudicial ao próprio organismo, ocasionando uma disfunção entendida como a perda do equilíbrio homeostático de excitabilidade e inibição cortical. Se a dor crônica desenvolvida pode ser considerada como mal adaptativa em termos fisiológicos, o que seria entendido como uma "disfunção do organismo" teve o efeito de produzir o encontro de Luana com o ambulatório especializado, sendo que o resultado da consulta pode ter sido determinante para influenciar na separação conjugal.

A compreensão da dor crônica não depende de lesões teciduais e, mesmo que elas existam, podem não gerar uma resposta dolorosa proporcional. Conforme a interpretação científica contemporânea, tais danos sequer seriam necessários para a ocorrência da dor, visto que a IASP define dor como “[...] uma experiência sensorial ou emocional desagradável associada a dano tecidual real ou potencial ou descrita em termos de tal dano" (MERSKEY; BOGDUK, 1994, p. 210, tradução minha). Esse conceito delimitado em poucas palavras vem acompanhado de uma extensa nota que circunscreve situações específicas sobre o que constitui esta experiência e enfatiza a relevância de questões geralmente atribuídas a fenômenos psicológicos ${ }^{5}$. A nota destaca que a dor seria sempre subjetiva e resultante de um aprendizado - portanto, dependente da experiência do paciente. Alguns grupos científicos têm expectativa de que novas tecnologias biomédicas

\footnotetext{
${ }^{4}$ A respeito de diferentes modelos de abordagem em clínicas de dor, ver Lima e Trad (2007), Jackson (2000) e Baszanger (1998). Para modelos divergentes de tratamento da dor com acupuntura, ver Toniol (2015).

" "Note: The inability to communicate verbally does not negate the possibility that an individual is experiencing pain and is in need of appropriate pain-relieving treatment. Pain is always subjective. Each individual learns the application of the word through experiences related to injury in early life. Biologists recognize that those stimuli which cause pain are liable to damage tissue. Accordingly, pain is that experience we associate with actual or potential tissue damage. It is unquestionably a sensation in a part or parts of the body, but it is also always unpleasant and therefore also an emotional experience. Experiences which resemble pain but are not unpleasant, e.g., pricking, should not be called pain. Unpleasant abnormal experiences (dysesthesias) may also be pain but are not necessarily so because, subjectively, they may not have the usual sensory qualities of pain. Many people report pain in the absence of tissue damage or any likely pathophysiological cause; usually this happens for psychological reasons. There is usually no way to distinguish their experience from that due to tissue damage if we take the subjective report. If they regard their experience as pain, and if they report it in the same ways as pain caused by tissue damage, it should be accepted as pain. This definition avoids tying pain to the stimulus. Activity induced in the nociceptor and nociceptive pathways by a noxious stimulus is not pain, which is always a psychological state, even though we may well appreciate that pain most often has a proximate physical cause". (MERSKEY; BOGDUK, 1994, p. 210)
} 
de neuroimagem possam vir a ser capazes de mensurar a dor, tarefa reconhecidamente de difícil viabilização e com problemas conceituais que não serão analisados neste $\operatorname{artigo}^{6}$.

Tendo especificado o conceito de dor e indicado a diversidade de elementos que precisam ser coordenados na produção de inteligibilidade médica do quadro doloroso, irei descrever a seguir como regiões do corpo podem ser percebidas em função da dor ou deixarem de ser percebidas em função do tratamento.

\subsection{Reagregando a Geografia Corporal}

Primeiramente lemos o prontuário da paciente, que já se tratava neste serviço de dor há um ano. Em função de um acidente, havia começado a sentir dores, que passaram a tomar conta de todo seu corpo. Ela entrou acompanhada do marido, tirou o casaco, largou sua bolsa e uma pasta com documentos médicos (receitas, exames, laudos) em uma das cadeiras disponíveis. Ficou em pé, em posição na qual seu corpo ficaria apto a cooperar com um exame. Um integrante da equipe de atendimento pediu que ela sentasse. Onde a dor era situada, quais cirurgias havia realizado, quais exercícios físicos praticava e como estava seu sono ultimamente foram questões proferidas levando em consideração a leitura prévia do prontuário. Perguntada sobre qual número em uma escala de intensidade de zero (sem dor) a dez (pior dor imaginável) corresponderia à dor que sentia, ela respondeu oito. Contou que andava caindo sozinha na rua, motivo pelo qual necessitava de acompanhamento em suas atividades cotidianas. Ela deitou-se na maca e foi examinada pelo fisioterapeuta e pela doutoranda, que pediram que ela fizesse determinados movimentos com o corpo.

O fisioterapeuta realizou um procedimento de massagem profunda com o auxílio de um utensílio enquanto ela suspirava devido à dor provocada. Logo após, ele pediu que a paciente fizesse os movimentos solicitados no início da consulta e todos ficamos impressionados com o grande aumento da mobilidade. Ele retomou o procedimento e, enquanto isso, seu marido fez um comentário aparentemente descontextualizado do assunto da consulta, que neste momento estava voltada à ação passiva sobre a musculatura. Ele contou que a esposa havia perdido um bebê em fase de gestação devido ao acidente mencionado. Ao fim do procedimento, a paciente comentou que nunca havia se sentido tão aliviada. "Quanto está a dor até dez?", perguntou dessa vez o marido, tentando assumir o critério analítico utilizado pelos profissionais. "Dois", ela disse, complementando com outra medida: "Há quase dez anos eu não sentia os meus pés". Posteriormente, na conversa com o preceptor que foi vê-la, o casal contou que não tinha filhos, mas pretendia realizar uma adoção, já que outros médicos teriam desaconselhado a gravidez em função das dores relatadas.

Essa descrição mostra que o tratamento para a dor crônica pode envolver desde a musculatura tensa até os planos familiares. Os relatos indicam o que nesse caso é dor crônica: organizar a família sem gestar um filho, caminhar sempre em companhia, não sentir uma parte do corpo durante anos. Procedimentos para combater a dor podem gerar dor, mas também resultado de alívio imediato. Este caráter aparentemente contraditório

\footnotetext{
${ }^{6}$ A esse respeito, ver Saretta (2019).
} 
ocasiona algumas tensões inclusive sobre o que é ou não é dor, como evidenciado na descrição a seguir, relativa ao atendimento de um paciente que sofreu a amputação de uma perna devido a um acidente de trânsito.

O problema de Laerte era "dor fantasma", conforme anunciou em sua primeira consulta, quando utilizou o termo técnico para se referir à dor percebida na região do corpo que não está fisicamente presente. Disse que sentia "dor na ponta do pé" da perna amputada, indicando com precisão a região que doía "como se um sapato fizesse os dedos se dobrarem". Ele reclamou também de dor nas costas, que atribuía a origem ao nervo ciático. O preceptor que foi vê-lo lhe propôs um tratamento de modulação do sistema nervoso por meio da Estimulação Transcraniana por Corrente Contínua (ETCC) combinada com a acupuntura neurofuncional. Aparentemente desconfiado, Laerte sugeriu que a dor fantasma seria relacionada ao cérebro, portanto, incapaz de ser resolvida. O seu prognóstico foi contraposto pelo preceptor ao exemplificar casos com desfechos positivos. Reflexivo, Laerte concluiu: “Não, o meu problema é só a dor nas costas, dessa eu quero me livrar. Da fantasma, eu já me acostumei. Quando eu não tenho dor fantasma, às vezes sinto até falta. Eu sou meio masoquista". O preceptor reforçou que o paciente poderia aderir ou não ao tratamento e explicou que, em relação à "outra dor", os medicamentos prescritos pelos profissionais do setor de fisiatria (os quais haviam o encaminhado ao Serviço de Tratamento da Dor) estavam adequados e poderiam apenas ser levemente alterados para terem maior eficiência.

Laerte decidiu se submeter à terapêutica proposta. Quando chegou à sessão de acupuntura na semana seguinte, afirmou que a "dor no ciático" estava lhe incomodando mais do que a "dor fantasma", mas sugeriu uma correlação, contraposta por outro preceptor que lhe atendeu neste dia e lhe explicou que seriam "dores distintas". O preceptor inseriu duas agulhas em suas costas, mencionando as regiões anatômicas aos doutorandos que assistiam ao procedimento, e pediu que Laerte segurasse um pequeno cano de metal conectado por um fio a um dispositivo que possuía outro fio cuja extremidade seria encostada na agulha. Ao estabelecer a corrente elétrica, o paciente deu um grito, o que fez o médico ajustar a intensidade no dispositivo e justificar a ação proveniente do estímulo. Laerte, então, perguntou levemente irritado se o médico estava ali para fazêlo sentir mais dor ou para extingui-la. O preceptor disse que o paciente poderia sentir algum desconforto no início. "Desconforto não é dor", lhe contrapôs imediatamente e prosseguiu falando de maneira correlacionada sobre suas dores, enquanto o preceptor insistia em considerá-las de tipos diferentes.

De maneira geral, tanto o paciente quanto o profissional se referiam à "dor do membro fantasma" e à "dor do [nervo] ciático" utilizando os mesmos termos. O preceptor explicou, simultaneamente, a ele e aos doutorandos os motivos que tecnicamente gerariam "a sensação de dor". Laerte o interrompeu: "Não é sensação, eu sinto dor!". Se já havia uma divergência entre a correlação das dores, desta vez a ênfase se dava na distinção entre dor e sensação. Quando terminou o tempo de estímulo previsto na etapa de agulhamento, o preceptor deixou a sala. Eu e um profissional da equipe (neste dia, casualmente um psicólogo) ficamos no ambiente onde este alocou os eletrodos de estimulação na cabeça do paciente. 
Laerte pareceu desconfiado de que a intensidade da estimulação transcraniana estava demasiadamente reduzida porque reclamara da intensidade na sessão de acupuntura. Ele enfatizou que a corrente elétrica estava muito fraca. O psicólogo disse que o tratamento consistia em uma estimulação daquela intensidade, não seria possível uma corrente elétrica maior para este tipo de procedimento. Explicou também que o uso da ETCC costuma ter resposta após diversas sessões, embora muitas pessoas já sentissem melhora na primeira vez. Laerte reconheceu que sua dor havia melhorado muito após a sessão de acupuntura e lamentou que houvesse se estressado: "A dor ativa o lado animal do cara". Como eu estava especialmente interessado no desdobramento de seu caso, acompanhei diversas sessões que estavam inicialmente previstas na frequência de duas vezes por semana. Ao final delas, ele afirmou que havia melhorado bastante, ainda que até então a dor relacionada ao membro fantasma não estivesse sido anulada como havia sido sua expectativa após a surpreendente melhora inicial.

Quando Laerte chegou pela primeira vez no serviço especializado em dor após ter realizado tratamento no setor de fisiatra do hospital, a reclamação de "dor fantasma" indicava um termo técnico que somente seria complementado no prontuário pelo membro amputado. No momento em que uma estimulação elétrica foi proposta como terapêutica, ele se mostrou receoso e sugeriu que a origem cerebral impediria algum tratamento. Embora inicialmente tenha se mostrado cético ao estímulo cerebral por corrente elétrica, fazia uso de medicações que almejavam também ação no "cérebro", mas possuíam a mediação da língua, da saliva, do estômago, da similaridade com outros medicamentos utilizados por ele e por pessoas de sua convivência. Ainda que preceptor e paciente concordassem que medicamento e estimulação transcraniana tivessem estratégias de ação diferentes, a região e o modo que a ação ocorreria não pareciam ser partilhados, nem mesmo as noções de sensação, de desconforto e de dor: em frente ao corpo do paciente que sentia dor, foi preciso distingui-las, pois não compunham um mesmo objeto.

Talvez pudessem compô-lo se a explicação tivesse sido feita após o procedimento ter ocasionado alívio ou em uma situação na qual o paciente não cogitasse que seu relato fosse dubitável. Entretanto, diante de um corpo doloroso cuja dor precisava ser comunicada por palavras - já que não era visível pelo olhar capaz de ver a ausência da perna, mas não a presença do pé -, a distinção não encontrava coordenação. Conforme destaca Mol (2002), objetos manipulados em prática não são os mesmos de um lugar a outro, por isso há pertinência de investigação: “E como diferentes objetos que são unidos em um mesmo nome evitam conflito e confrontações explosivas? E será que, mesmo que haja tensões entre eles, várias versões de um objeto, às vezes, dependem uma da outra?" (MOL, 2002, p. 5-6, tradução minha). Nesse sentido, a dor não era a mesma quando tratada como sensação no primeiro procedimento terapêutico a que Laerte se submeteu.

Nos dois tratamentos para dor distintos narrados nesta seção, os procedimentos alteraram inversamente o momento que pacientes poderiam sentir partes do corpo. Uma paciente passou a sentir o pé que não percebia há uma década, enquanto outro deixou de sentir com frequência a presença da dor e, simultaneamente, do pé amputado: geografias corporais foram modificadas pelos envolvidos. 


\subsection{Reagregando o Corpo Laboral}

A associação da dor crônica com sintomas de ansiedade e de depressão costuma ser frequente. Tais condições comporiam o quadro doloroso e tenderiam a estimular outros fatores prejudiciais, tais como o isolamento social, a dificuldade de vínculo trabalhista e a angústia que a dor não possa ser amenizada. Em algumas situações, as separações biopsicossociais em torno do objeto de tratamento parecem mais demarcadas e sua inteligibilidade dispensaria uma discussão entre colegas preceptores, como foi um caso no qual o preceptor salientou à equipe que a paciente estaria recebendo um tratamento inadequado por ser direcionado apenas para os sintomas, sem cuidar da "doença de base", a qual demandaria um tratamento de estabilização de humor. O preceptor indicou a prescrição de um medicamento, mas logo mudou de ideia porque seu uso necessitaria ter um bom acompanhamento psiquiátrico. Então, determinou à equipe a prescrição de outra medicação para os sintomas dolorosos e a escrita de uma carta, destinada ao psiquiatra particular ou à Unidade Básica de Saúde, salientando ser indispensável a melhora do tratamento psiquiátrico "SEM O QUAL NÃO MELHORARÁ A DOR". Conforme me foi explicado, as letras maiúsculas foram solicitadas com o intuito de ênfase e de estímulo à leitura pela paciente para que tivesse clareza a este respeito.

Se há casos como esse nos quais há uma evidente prioridade de componentes psiquiátricos, as distinções e correlações entre o biológico, o psicológico e o social nem sempre operam de maneira tão estável na racionalidade de orientação biomédica relacionada à dor crônica. Por isso, gostaria de sugerir que esses aspectos também parecem passíveis a modulações. Nesse sentido, irei descrever a consulta de Anderson, a quem o médico residente, a partir da leitura do prontuário, sugeriu uma vaga associação entre a depressão que o paciente tivera e a dor que motivava aquele encontro. Anderson prontamente respondeu: "Uma coisa não tem nada a ver com a outra". A dor crônica só teria iniciado após um acidente de trabalho no ramo da construção civil. O residente mostrou-se compreensivo e explicou-lhe que, às vezes, os sintomas se associam, mas respeitou a distinção feita pelo paciente durante toda consulta bem como no modo de expor o caso ao preceptor. Inclusive, chegou a destacar que considerou Anderson parecia "uma pessoa bem centrada", o que facilitaria a análise e, por sua vez, o tratamento.

Nesta época, Anderson trabalhava em um ramo de atividade profissional diferente daquele no qual se acidentara. Seu chefe era compreensível com sua condição física e havia lhe colocado em uma função na qual as atividades de maior esforço físico podiam ser evitadas, ainda que fosse uma atividade que eventualmente exigia levantamento de peso. Para isso, ele seguia as orientações que recebeu na Escola de Coluna, localizada no setor de fisiatria do hospital universitário, para a qual fora encaminhado pelo próprio Serviço de Tratamento da Dor. Ele também havia iniciado a prática de exercícios aquáticos e tomava as medicações exatamente conforme haviam sido prescritas. Sendo assim, Anderson era considerado um paciente com alta adesão ao tratamento e que tinha tido melhora expressiva no seu quadro clínico.

Na consulta descrita, os profissionais deram a opção de aumentar a dose da medicação em uso para evitar algumas leves crises de dor que persistiam, já que as crises agudas estavam controladas pela dosagem em uso e pela prática de exercício físico indicada 
anteriormente. Entretanto, alertaram que o aumento da dose poderia ocasionar efeitos colaterais como tontura ou sonolência. Anderson decidiu pela manutenção porque julgava que "já tomava muito remédio", consideração comum a pacientes crônicos, sobretudo em razão de problemas estomacais recorrentes ${ }^{7}$. A avaliação de que o estado emocional do paciente estaria equilibrado, sem que seu relato ou seu comportamento durante a consulta indicassem alguma desconfiança, tornou seu histórico de depressão parcialmente independente da analítica do seu quadro doloroso.

Muitos meses depois, quando acompanhei um grupo de doutorandas relatando um caso a um preceptor, percebi que se tratava de Anderson. Esta provavelmente seria sua segunda (no máximo, a terceira) consulta após à descrita anteriormente, que fora discutida com outro preceptor. O relato das doutorandas informava que o paciente estava desempregado há meses e queria entrar na justiça para obter benefício assistencial. O preceptor mostrou uma expressão de suspeita de um possível "ganho secundário". Neste momento, a discussão de seu caso foi brevemente interrompida por uma consultoria que necessitava auxílio para o ajuste na medicação de um paciente do setor de emergência.

Enquanto isso, as doutorandas discutiram entre si. Uma delas caracterizava o quadro clínico como síndrome da dor miofascial, ocasionada na musculatura por nódulos que causam dor em outras regióes do corpo. Um doutorando rejeitava convictamente esta opção, o que gerou desacordo sobre possíveis razões da irradiação da dor para o abdômen, as costas e as regiões genital e anal. Desde a primeira consulta que acompanhei, eu considerava que questões sobre orientação sexual pareciam influenciar as suas relações profissionais, especialmente pelo fato de que não poderia carregar peso em um ambiente bastante marcado pela virilidade masculina. Somente manifestei minhas impressões posteriormente a esta consulta, visto que a inteligibilidade do seu caso ainda não havia encontrado conflito.

O preceptor retornou da consultoria e as doutorandas retomaram o relato e destacaram que nenhum dos exames entregues pelo paciente indicava alteração que justificasse a dor. O preceptor os analisou e decidiu vê-lo, embora estivesse sobrecarregado de atividades devido à ausência de outro colega por motivo de doença. Ao chegar no consultório, questionou se Anderson não teria condições de trabalhar. Ele justificou que trabalhara em uma atividade não exigia tanto esforço físico, mas foi despedido devido à reconhecida crise econômica que atravessava o país. Anderson, então, foi assertivo ao afirmar que a dor não lhe permitiria realizar nenhuma atividade que precisasse segurar peso, o que estaria inviabilizando as escassas oportunidades profissionais.

O preceptor disse que estava um pouco confuso sobre a conduta, pois não sabia precisar a origem das dores que ele relatava naquele momento, já que não lhe parecia que fosse devido à queda. Contrariado, Anderson respondeu que não a sentia antes desse fato. O preceptor citou todos exames que haviam sido realizados e que não indicaram nenhuma anormalidade. Afirmou, então, que a equipe precisaria estudar o seu prontuário com calma, pois não sabia se aquele Serviço de Tratamento de Dor teria ainda capacidade de beneficiá-lo, visto que ele estaria há muito tempo com este vínculo, teria tido uma importante melhora e poderia manter a renovação das prescrições via Unidade Básica de

A respeito da relação com os medicamentos por parte de pacientes diagnosticados com doenças crônicas, ver o dossiê organizado por Fleischer e Franch (2015) e Fleischer (2014). 
Saúde. Pediu que ele retornasse no dia seguinte em um atendimento especial, pois teria a presença de outros preceptores para uma análise coletiva. Como o paciente necessitava solicitar com antecedência a autorização da prefeitura de sua cidade para ter direito ao transporte intermunicipal até o hospital universitário, seu retorno ficou agendado para o mês seguinte.

Anderson requereu a atualização do laudo a pedido do seu advogado, o que gerou desconforto no preceptor, que leu em voz alta o laudo antigo. Ele afirmou que a nova versão indicaria dor crônica, mas que seria retirado o trecho que se referia a dano póstraumático, pois não sabia se o motivo da dor, que persistia, ainda seria devido ao trauma. Isto é, se a dor desenvolvida após a queda ainda teria relação fisiológica com este dano, ainda que este evento tenha sido o marco temporal para o início da dor. A preocupação com os termos na nova descrição do laudo era evitar um papel de perícia em uma situação que parecia duvidosa. Quando o preceptor estava de saída para deixá-lo acompanhado das doutorandas que registrariam as informações no prontuário e renovariam as receitas de medicamentos controlados, Anderson disse com expressão de tristeza: "Dr., não é fácil!".

O caso de Anderson parece sugerir que a disposição dos fatores necessita coordenação: a racionalidade clínica da dor envolve coletivo de médicos, peritos, a compreensão do chefe, a prática de exercícios físicos, a adesão às medicações, a prefeitura do munícipio de origem, a demanda de um advogado e a crise financeira do país. A possibilidade de dano pós-traumático como resultado de uma queda de determinada altura é unânime entre médicos, leigos, construtores civis. No entanto, as articulações que a dor pode produzir pela cronicidade seriam mais complexas e dependeriam de exames, comportamento, disposição, leis trabalhistas, bolsa de valores. Diversos elementos podem influenciar o corpo do paciente, tanto "endógenos" quanto "exógenos". Nesse sentido, a dor crônica parece evidenciar a pertinência de que o corpo deve ser compreendido analiticamente pela sua capacidade de afetar e de ser afetado (DESPRET, 2011; LATOUR, 2008). Desse modo, o corpo é entendido como

[...] uma interface que vai ficando mais descritivel quando aprende a ser afetado por muitos mais elementos. Não faz sentido definir o corpo diretamente, só faz sentido sensibilizá-lo para o que são estes outros elementos. (LATOUR, 2008, p. 39, grifos do autor)

No caso em análise, os limites de endogenia e exogenia do corpo pareciam não encontrar coordenação: para Anderson, assim como para outros pacientes, a dor crônica é um problema conjunto, que articula trabalho com acidente, com o benefício, com a prefeitura, com a família. Para a análise médica, que compreende a relevância de todos estes fatores em seu modelo biopsicossocial, seria preciso discernimento dos fatores que estariam gerando a dor naquele momento, fossem eles psíquicos, biológicos e/ou sociais, para a construção de uma estratégia terapêutica que poderia ser voltada à musculatura, ao sistema nervoso, às atitudes comportamentais, às relações afetivas, etc. O que gostaria de destacar é que, se o evento (acidente) foi o marco temporal para o paciente e para a equipe profissional, as articulações que o envolvem necessitam ganhar existência, seja pelo relato, pelo exame físico, pela arguição do advogado, pela disponibilidade da agenda do transporte intermunicipal que fornece o acesso aos profissionais para avaliá-lo. 
A temporalidade da queda é dependente das articulações com o corpo para que o trauma tenha fim. A evidência de um laudo exige por sua natureza a circunscrição do corpo e a delimitação de quais afetos são capazes de sensibilizá-lo.

Também de um laudo com diagnóstico precisava Tereza, paciente em que o atendimento foi mediado pelo mesmo preceptor, que estava tentando obter benefício assistencial. Ela explicou que estava afastada do trabalho sem receber auxílio. Havia tentado voltar a trabalhar mesmo com as dores que sentia, mas o médico da empresa havia vetado por ausência de condições laborais. Os donos da empresa para a qual trabalhava, cientes da sua incapacidade funcional para o trabalho, haviam lhe sugerido que entrasse com uma ação judicial requerendo auxílio do Estado.

Como medida terapêutica para as queixas de dor, o preceptor cogitou retomar um antidepressivo que havia sido substituído em consulta anterior, motivo pelo qual questionou a paciente se ela se considerava uma pessoa muito preocupada, o que foi confirmado, mas também justificado: Tereza cogitava que teria relação com a infância, período em que trabalhava na roça. Sentia-se injustiçada de estar sem renda, apesar de ter trabalhado durante toda sua vida até então. Ela falava de maneira calma e reflexiva, como se fosse um desabafo consolado. Contou que sofria também por ter um filho com deficiência cognitiva e por não conseguir ajudá-lo na escola, pois ela havia estudado somente até a segunda série do ensino fundamental.

Após a conclusão da consulta, o preceptor chamou as doutorandas que haviam atendido inicialmente a paciente para destacar o caráter biopsicossocial da dor. Salientou que há casos de dor crônica nos quais seria preferível entender o contexto social do que priorizar o exame, diferentemente da dor aguda. Embora quando consultado na discussão de caso tivesse cogitado um plano de alta para Tereza, quando lhe atendeu pessoalmente considerou esta opção inviável. Assim, a nova conduta seria primeiramente tentarem melhorar o benefício das medicações (definição de forma, dosagem e combinação capaz da paciente se adaptar conciliada ao fornecimento público gratuito) para que no futuro ela mantivesse a continuidade do seu atendimento e realizasse a renovação das receitas na própria Unidade Básica de Saúde, onde, conforme relatado durante o atendimento, parecia haver uma médica atenciosa com a qual a paciente teria um bom relacionamento.

Os quadros clínicos dolorosos de Anderson e de Tereza eram muito diferentes, mas ambos de alguma maneira correlacionavam no consultório as características da dor crônica e do sistema previdenciário brasileiro. Ainda que os profissionais de saúde do serviço diversas vezes emitam laudos que poderão ser utilizados em favor do afastamento do trabalho, a depender da avaliação da perícia médica previdenciária, eles tomam cuidado para que o Serviço de Tratamento de Dor não seja utilizado por interesses escusos, considerando que a dor poderia ser forjada, visto que sua avaliação depende primeiramente das informações oferecidas pelos pacientes e é difícil a comprovação de sua existência (e, por sua vez, da sua intensidade) por medidas consideradas objetivas.

Em certa medida, o risco de "ganho secundário" faz parte do quadro de dor, pois compõe sua delimitação e a estratégia do tratamento clínico, já que a inexistência ou a presença de uma pretensa vantagem indevida contribui para inteligibilidade ou mesmo para o reconhecimento da realidade da dor crônica. Sendo assim, os profissionais costumam ficar atentos a diversas características do comportamento dos pacientes e de seus relatos 
durante o atendimento. A suspeita não costuma se dar a priori, mas pode ser ativada a partir de qualquer fato considerado duvidoso. Por exemplo, foi o caso de uma situação na qual um doutorando desconfiou da sonolência relatada por um paciente: se sua dor fosse tão intensa, ele supunha, o paciente não poderia dormir com uma dose tão baixa de medicação - em outro contexto vi um preceptor fazer uma inferência muito similar, mas relacionada a um paciente já bem conhecido pelo serviço. No entanto, a desconfiança do doutorando carecia de articulação suficiente, então, o preceptor destacou que algumas pessoas poderiam ter intolerância mesmo a dosagens baixas, mas recomendou-lhe que sua percepção fosse registrada na seção de "impressões" do prontuário.

Embora haja, por um lado, precaução da equipe médica em relação à solicitação de laudos, por outro lado, esses profissionais reconhecem a importância do benefício previdenciário para a efetiva melhora de alguns pacientes ao propiciar, por exemplo, a interrupção de determinadas atividades laborais prejudiciais, a viabilização do acesso a um medicamento adequado quando este não é fornecido pelo Sistema Único de Saúde ou a execução de exercícios físicos adequados. Mesmo que a dor seja compreendida como sendo biopsicossocial, a precisão do laudo fornecido pelo serviço parece tecnicamente pretender se restringir ao fenômeno biológico. Assim, para outros casos, a doença referida tende a ser dor crônica, categoria genérica, reconhecida como diagnóstico, mas que não costuma lograr êxito por si mesma na reivindicação de direitos previdenciários.

Dentro das doenças caracterizadas pela presença de dor crônica, existe um diagnóstico específico cuja complexidade dos fatores psicossociais costuma ser bastante reconhecida: a fibromialgia. Nesse sentido, a doença se enquadra dentre aquelas que Alameda Cuesta (2014) chama de doenças contestadas, nas quais a afirmação de sua realidade carece de demarcadores biológicos, motivo pelo qual há profissionais que não as reconhecem enquanto diagnósticos legítimos - o que não era o caso dos profissionais do serviço onde fiz etnografia. Embora eu não tenha explorado neste artigo esta parte do meu campo de pesquisa (SARETTA, 2019), acompanhei situações similares às descritas por Cuesta nas quais os próprios pacientes tinham a expectativa da descoberta de um elemento biológico que justificasse suas dores e lhes permitissem comprovar a realidade delas. Por esse motivo, chegavam a solicitar exames, sobretudo imagéticos, mesmo quando médicas não reconheciam indicativos clínicos para este tipo de requisição. Desse modo, convém destacar que alguns pacientes também corroboram com a produção da realidade assentada em características compreendidas como biológicas com receio de que aspectos psicossociais sejam deslegitimados por uma suposta intencionalidade que poderia ser evitada.

\section{Considerações Finais}

O tratamento médico da dor crônica parece exigir o reconhecimento de um corpo articulado, capaz de ser afetado por relações familiares, pela arquitetura da residência, pelo sono, pelo sistema nervoso, pelas suspeitas de sua veracidade. Sua avaliação perpassa uma diversidade de materialidades (tais como a agulha, o algodão, a maca, o músculo) que precisam ser mobilizadas junto ao testemunho do paciente para a produção de coordenações capazes de delimitar fronteiras biossociais. O corpo com dor crônica 
delimitado em uma consulta se mostra atravessado por políticas públicas, relações familiares, estratégias econômicas e desejos diversos, por isso se constitui em um corpo resistente ao completo isolamento analítico dos fatores discriminatórios capaz de estabilizar biologia, psicologia e relações sociais.

O modelo de análise biopsicossocial analisado, embora tenha a pretensão de abranger o corpo como um todo, parece passível de ser compreendido pelo aspecto dual "biopsi" (aspectos biológicos conjugados a problemas tradicionalmente vistos como psicológicos, cada vez mais compreendidos como neuroquímicos) e "psicossocial" (melhor compreendido pelo caráter excludente de tudo aquilo que não é biológico, contemplando especialmente o comportamento do paciente diante do sofrimento doloroso e as demais relações entendidas como sociais). No entanto, uma análise a partir do encontro clínico parece sugerir que noções de social, de biológico e de psicológico são constituídas no consultório diante do corpo com dor e de seu testemunho de maneira bem mais fluida do que estavam sendo mobilizadas no congresso mundial de dor que estive presente, conforme referenciado na introdução deste artigo. Assim, gostaria de sugerir que o modelo de análise biopsicossocial orientado pela biomedicina parece conceber uma união de fatores causais na composição da dor concedendo primazia ontológica à biologia, mas a produção de inteligibilidade desses fatores, quando analisada pelos enactments da prática clínica, indica que o biológico e o social não se sustentam a priori: diferentes corpos - e, consequentemente, diferentes concepções de biologia e de relações sociais podem ser articulados no reconhecimento da existência da dor crônica. Nesse sentido, parece possível sugerir que aspectos entendidos como biológicos, psicológicos e sociais também sofrem modulações no encontro clínico.

Se o reconhecimento da expressão "social" nos sintomas da dor crônica aparentemente é visto por muitas especialidades médicas como uma desvantagem analítica porque impediria um tratamento ideal de um corpo bem delimitado, isto também pode ser um indicativo de que a dor crônica é um objeto privilegiado para reconhecer a existência de um corpo múltiplo. Isso permite que viemos a especular outros tipos de articulações biopsicossociais nas quais os termos não se unam por uma junção inclusiva, mas se articulem por meio de fronteiras de disciplinas indisciplinadas - isto é, capazes de afetarem umas às outras.

\section{Referências}

BASZANGER, Isabelle. Pain Physicians: All Alike, All Different. In: BERG, M.; MOL, A. (org). Differences in medicine: unraveling practices, techniques, and bodies. Carolina do Norte: Duke University Press, 1998. p. 119-143.

BERG, Marc; AKRICH, Madeleine. Introduction-bodies on trial: performances and politics in medicine and biology. Body \& Society, [s.l.], v. 10, n. 2-3, p. 1-12, 2004.

BERG, Marc; MOL, Annemarie. Differences in Medicine: An Introduction. In: BERG, M.; MOL, A. (org.) Differences in medicine: unraveling practices, techniques, and bodies. Carolina do Norte: Duke University Press, 1998. p. 1-12. 
CUESTA, Alameda. Malestares en el margem: sujetos y trânsitos en la fibromialgia, el síndrome de fatiga crónica y la sensibilidade química multiple. 2014. 373p. Tesis (Doctoral) Universidade autônoma de Madrid, Madrid, 2014.

DELEUZE, Gilles; GUATTARI, Félix. Mil platôs: capitalismo e esquizofrenia. São Paulo: Editora 34, 1995. v. 1.

DELEUZE, Gilles; GUATTARI, Félix. Como criar para si um corpo sem órgãos. In: DELEUZE, Gilles; GUATTARI, Félix. Mil platôs: capitalismo e esquizofrenia. São Paulo: Editora 34, 1996. v. 3. p. 9-31.

DESPRET, Vinciane. The body we care for: Figures of anthropo-zoo-genesis. Body $\boldsymbol{\delta}$ Society, [s.l.], v. 10, n. 2-3, p. 111-134, 2004.

DESPRET, Vinciane. Os dispositivos experimentais. Fractal: Revista de Psicologia, [s.l.], v. 23, n. 1, p. 43-58, 2011.

FLEISCHER, Soraya. O Grupo da Pressão: notas sobre as lógicas do controle de doenças crônicas na Guariroba, Ceilândia/DF. Amazônica - Revista de Antropologia, [s.l.], v. 5 , n. 2, p. 452-477, 2014.

FLEISCHER, Soraya; FRANCH, Mónica. Uma dor que não passa: aportes teóricometodológicos de uma antropologia das doenças compridas. Revista de Ciências SociaisPolítica \& Trabalho, [s.l.], v. 1, n. 42, 2015.

GATCHEL, Robert J. et al. The biopsychosocial approach to chronic pain: scientific advances and future directions. Psychological bulletin, [s.l.], v. 133, n. 4, p. 581-624, 2007.

GOOD, M. J. D.; BRODWIN, P.; GOOD, B.; KLEINMAN, A. (ed.). Pain as human experience. California: Berkeley University of California Press, 1992.

GUERCI, A.; CONSIGLIERE, S. Por uma antropologia da dor: nota preliminar. Ilha - Revista de Antropologia, Florianópolis, v. 1, n. 1, 2, p. 57-72, 1999.

HARAWAY, Donna. Manifesto Ciborgue: Ciência, tecnologia e feminismo-socialista no final do século XX. In: TADEU, Tomaz (org.). Antropologia do Ciborgue: as vertigens do póshumano. Belo Horizonte: Autêntica Editora, 2009. p. 33-118.

JACKSON, Jean. Camp pain: talking with chronic pain patients. Philadelphia: University of Pennsylvania Press, 2000.

LATOUR, Bruno. Reassembling the social: an Introduction to Actor-Network-Theory. Oxford University Press, New York, 2005.

LATOUR, Bruno. Como falar do corpo? A dimensão normativa dos estudos sobre a ciência Objectos impuros: experiências em estudos sobre a ciência. Porto: Afrontamento, 2008.

p. 39-61.

LE BRETON, David. Antropologia da dor. São Paulo: Fap-Unifesp, 2013. p. 248.

LIMA, Mônica; TRAD, Bomfim. A dor crônica sob o olhar médico: modelo biomédico e prática clínica. Cadernos de Saúde Pública, [s.l.], v. 23, n. 11, p. 2.672-2.680, 2007.

LOCK, Margaret; NGUYEN, Vinh-Kim. Technologies and Bodies in Context and Local Biologies and Human Difference. In: LOCK, Margaret; NGUYEN, Vinh-Kim. An anthropology of biomedicine. United Kigdom: John Wiley \& Sons, 2010. p. 15-110.

MAUSS, Marcel. As técnicas do corpo. Sociologia e Antropologia, [s.l.], p. 399-422, 2003.

M'CHAREK, Amade. Fragile differences, relational effects: Stories about the materiality of race and sex. European Journal of Women's Studies, [s.l.], v. 17, n. 4, p. 307-322, 2010. 
MERSKEY, Harold; BOGDUK, Nikolai. Classification of chronic pain, IASP Task Force on Taxonomy. In: MERSKEY, Harold; BOGDUK, Nikolai. Part III: Pain Terms, a Current List with Definitions and Notes on Usage. Seattle, WA: International Association for the Study of Pain Press, 1994. p. 209-214. Disponível em: https://www.iasp-pain.org/Education/Content. aspx?ItemNumber $=1698$ \&navItemNumber $=576$. Acesso em: 3 mar. 2019.

MOL, Annemarie. The body multiple. Carolina do Norte: Duke University Press, 2002.

MOL, Annemarie. Política ontológica: algumas ideias e várias perguntas. In: NUNES, J. Arriscado; ROQUE, R. (ed.). Objectos impuros: experiências em estudos sociais da ciência. Porto: Edições Afrontamento, 2008. p. 63-106.

PATEL, Nilesh. Fisiologia da dor. In: KOPF, Andreas; PATEL, Nilesh (org.). Guia para o Tratamento da Dor em Contextos de Poucos Recursos. IASP Press, Seattle, 2010. p. 9-13.

ROHDEN, Fabíola. Os Hormônios te Salvam de Tudo": Produção de subjetividades e transformações corporais com o uso de recursos biomédicos. Mana, Rio de Janeiro, v. 24, n. 1, p. 199-229, 2018a.

ROHDEN, Fabíola. Considerações teórico-metodológicas sobre objetos instáveis e ausências presentes: analisando processos de materialização do desejo feminino. In: SEGATA, Jean; RIFIOTIS, Theophilos (org.). Políticas etnográficas no campo da ciência e das tecnologias da vida. Porto Alegre: UFRGS; ABA, 2018b. p. 135-158.

SARETTA, Mário Eugênio. Feitos e efeitos do placebo: corpo, dor e realidade a partir da antropologia social. 2019. 294p. Tese (Doutorado em Antropologia Social) - Programa de Pós-Graduação em Antropologia Social da Universidade Federal do Rio Grande do Sul, Porto Alegre, 2019.

STENGERS, Isabelle. A invenção das Ciências Modernas. São Paulo: Editora 34, 2002.

STENGERS, Isabelle. Cosmopolitics VII: the Curse of Tolerance. London: University of Minnesota Press, 2011 . p. 303-416.

TRACEY, Irene; MANTYH, Patrick, The cerebral signature for pain perception and its modulation. Neuron, [s.l.], v. 55, n. 3, p. 377-391, 2007.

TONIOL, Rodrigo. Do espírito na saúde: oferta e uso de terapias alternativas/ complementares nos serviços de saúde pública no Brasil. 2015. 302p. Tese (Doutorado) Universidade Federal do Rio Grande do Sul, Porto Alegre, 2015.

\section{Mário Eugênio Saretta}

Cientista social e documentarista, mestre e doutor em Antropologia Social pelo PPGAS/UFRGS. Integrante do grupo de pesquisa Ciências na Vida: Produção de Conhecimento e Articulações Heterogêneas (PPGAS/UFRGS) e professor de antropologia social na Escola de Música e Belas Artes do Paraná (UNESPAR).

E-mail:msaretta@gmail.com

ORCID: https://orcid.org/0000-0002-4224-3129

\section{Como referenciar este artigo:}

SARETTA, Mário Eugênio. Reagregando o Biopsicossocial: a clínica da dor sob análise etnográfica. Ilha - Revista de Antropologia, Florianópolis, v. 23, n. 2, p. 95-114, maio, 2021. 